(206)

\title{
Sustainable Way to Minimize the Solid Fabric Wastes using Peroxidase Extracts of Ipomoea palmate Forssk. and Saccharum officinarum L.
}

\author{
Abeysinghe A.A.P.H. ${ }^{1 *}$, Munasinghe M. ${ }^{1}$, Appuhamy A. ${ }^{2}$ \\ ${ }^{1}$ Department of Botany, University of Sri Jayewardenepura, Sri Lanka \\ ${ }^{2}$ MAS Fabrics (PVT) Ltd, MAS Fabric Park, Thulhiriya, Sri Lanka \\ *pevindu.abeysinghe@gmail.com
}

\begin{abstract}
One of the major environmental problems currently existing in the Sri Lankan apparel Industry is the aggregation of huge amounts of solid fabric wastes. This study was conducted to find out the optimum time and concentration taken to decolorise solid fabric wastes and investigate reuse and recycle methods of fabrics in order to minimise the impact upon the environment. The decolorisation was practiced by the peroxidase extracts of Ipomoea palmate Forssk. and Saccharum officinarum L. which are abundantly found in home gardens of Kandy District and Kurunegala District. The purification of biomolecules was done by a novel yet simple method of purification known as Three-Phase Partitioning (TPP). Butanolwater solvent system was used in this method. The concentration of purified solvents was measured using Potassium Permanganate and were tested upon Polyester and Cotton fabrics. The decolorisation activity shown in I. palmate extract was higher than that of S. officinarum. The highest decolorisation capacity was shown for a concentration of $1.6375 \times 10^{-5} \mathrm{~mol} \mathrm{dm}^{-1}$ of I. palmate extract, and a minimum time of 9 days was taken for complete decolorisation. For $S$. officinarum extract, it has taken a minimum time of 15 days for a concentration of $3.125 \times 10^{-6} \mathrm{~mol} \mathrm{dm}^{-1}$. The decolorisation capability was measured using a standard colour matrix. A slight deviation of peroxidase contents was observed in the plant materials collected from Kandy District and in Kurunegala District. Without aggregating huge amounts of solid wastes to the environment it has been stressed out that using simple and cheap methods of managing the solid fabrics in sustainable ways can minimize the damage on the environment by this study.
\end{abstract}

Keywords: Decolorisation, Solid fabric waste, Ipomoea palmate, Saccharum officinarum, Three phase partitioning 